\title{
CAERULOPLASMIN AS DEMONSTRATED BY STARCH GEL ELECTROPHORESIS
}

\author{
BY
}

\author{
J. N. CUMINGS AND C. J. EARL \\ From the Department of Chemical Pathology, The National Hospital, Queen Square, London
}

(RECEIVED FOR PUBLICATION JUNE 12, 1959)

\begin{abstract}
Starch gel electrophoresis has demonstrated that graded concentrations of sodium sulphate do not precipitate the serum globulins in any reasonable degree of purity.

The use of this form of electrophoresis has shown that caeruloplasmin is associated with a globulin in the $\mathrm{Fa}_{2}$ position.

This technique can be employed as a screening test for patients suspected of suffering from hepatolenticular degeneration.
\end{abstract}

Thompson and Watson (1949), utilizing graded concentrations of sodium sulphate for precipitating the various globulins of blood serum, demonstrated that copper appeared to be linked with each of the three main globulins. These observations were confirmed by Cumings, Goodwin, and Earl (1955) in normal subjects, and they also reported on the findings in patients with hepatolenticular degeneration using the same procedure. The oxidase activity of each globulin fraction in normal subjects was also estimated, using paraphenylenediamine as the substrate, and most activity was detected in the $\beta$ fraction.

These findings are at variance with a commonlyaccepted view that caeruloplasmin, the coppercontaining globulin possessing oxidase activity, is an $\alpha_{2}$ globulin complex.

The introduction of starch gel electrophoresis as developed by Smithies (1955) and the possibility of staining such gels for caeruloplasmin suggested a new approach to the problem, and the results of some investigations on these lines are recorded in this paper.

\section{Methods}

Starch electrophoresis was carried out by the method of Smithies (1955) using a block measuring $22.5 \times 3.8 \times 0.6 \mathrm{~cm}$. and run overnight at a voltage of 120 with a current of $0.44 \mathrm{~mA} / \mathrm{cm}$. width. After cutting the block as recommended it was stained for protein in the manner described by Smithies. For the staining of caeruloplasmin the technique of Uriel (1958) was followed.

Globulin fractions were prepared as in the previous paper, and they and serum were absorbed on to small pieces of Whatman $3 \mathrm{MM}$ paper, and these were inserted into the starch blocks. In some experiments paper electrophoresis of serum in duplicate was carried out. One of the two strips was stained for protein and appropriately sized pieces of paper from the unstained strip were cut out to correspond with $\alpha, \beta$, or $\gamma$ globulin and inserted into starch blocks.

\section{Results}

Electrophoresis of normal serum in starch yielded results similar to those obtained by Smithies, and his terminology is used throughout.

It was found that the globulin fractions, as prepared by sodium sulphate precipitation, when run in starch were not as pure as they appeared to be on paper electrophoresis. Four such experiments were performed and all gave similar results, one of which is illustrated in Fig. 1.

The strip representing $\gamma$ globulin $(15 \%$ salt) is seen to show only that globulin by both methods of electrophoresis. The fraction containing $\gamma$ and $\beta$ globulin (19\% salt), although apparently only containing these globulins on paper, is seen in starch to contain in addition a well-marked $\mathrm{S} \alpha_{2}$ globulin band and a small amount of $F \alpha_{2}$ globulin.

All the globulins are present in the starch gel and on paper electrophoresis in the fraction precipitated by $26 \%$ sodium sulphate; there is, however, more albumin demonstrated in starch than on paper.

All these various starch blocks were also stained for caeruloplasmin, and while no activity, as indicated by the brown colour of the Bandrowski base, was seen in the fraction precipitated by $15 \%$ salt, it was present in both the other two fractions. This test is inconclusive 
in view of the mixture of globulins shown by the results of the starch electrophoresis.

In order to determine the site of caeruloplasmin relative to the globulins two techniques were employed. First, portions of paper each containing one of the globulins obtained from paper electrophoresis of serum were inserted into starch blocks, run overnight and stained for protein and for caeruloplasmin. Fig. 2 demonstrates one of the five results obtained.

A stained band of caeruloplasmin is present in serum and in the $\alpha$ globulin fraction and appears in the $F \alpha_{2}$ position in the starch gel. No such stained band was obtained in any experiment from either the $\beta$ or the $\gamma$ portions of the paper electrophoretic strips.

The second method employed was to run serum in a starch gel, and, before dividing the gel into two portions, to punch out a series of holes along the starch block. This is necessary, as during the process of protein staining the gel contracts a little, so that it is not possible otherwise to match exactly the two strips stained by both methods. The starch blocks were then stained, and, by noting

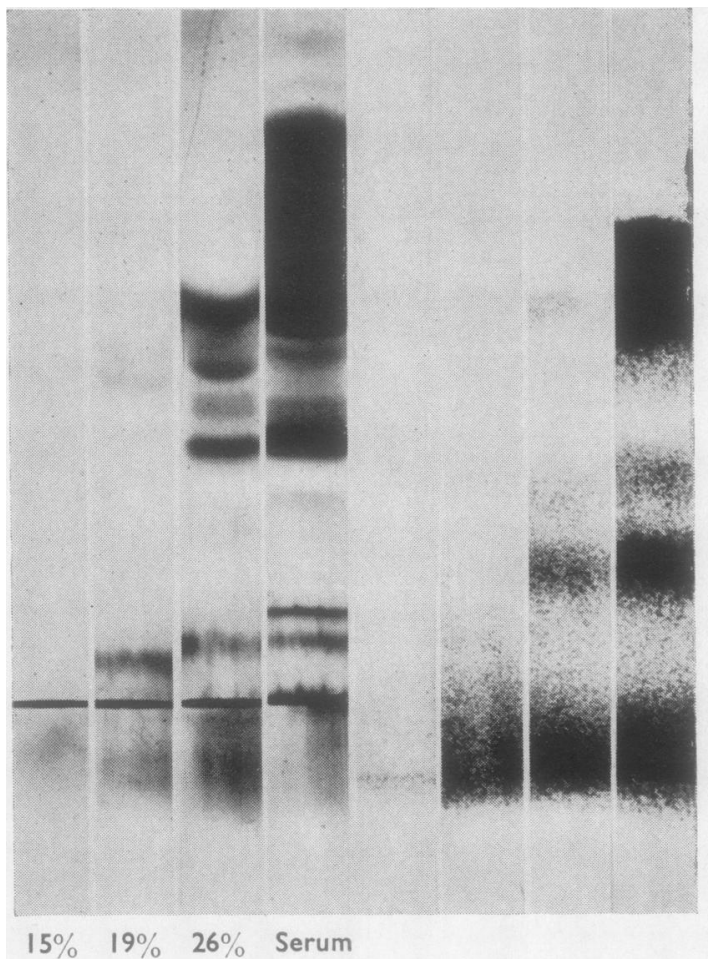

FiG. 1.-Normal serum and globulins obtained by salt precipitation run in starch (left) and on paper (right). The four paper strips are in the same order as the starch gels.

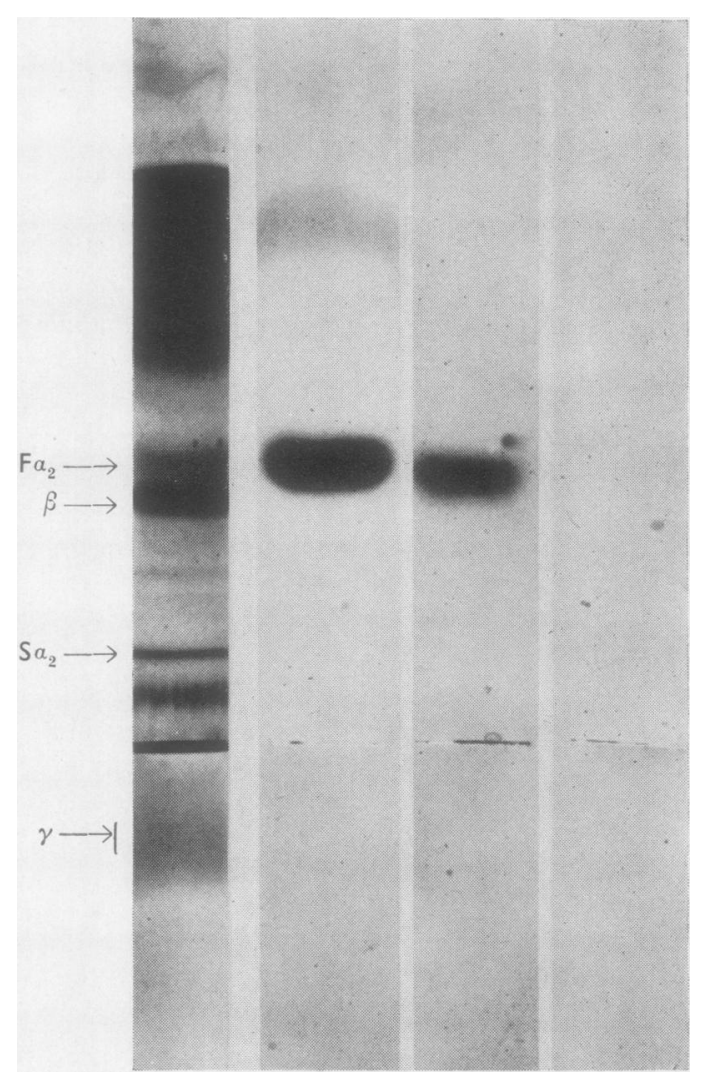

FIG. 2. Starch gel electrophoresis of normal serum (two on left), of $\alpha$ globulin (second from right), and of $\beta$ globulin (on right). The three on the right stained for caeruloplasmin and the one on the left for protein.

the positions of the various bands in relation to the number of the holes, it was demonstrated in three cases that the caeruloplasmin band corresponded to the $F \alpha_{2}$ position.

\section{Discussion}

It has been stated by Bearn and Kunkel (1954) as a result of their experiments that the copper in $N$ the blood is attached to an $\alpha_{2}$ globulin. Holmberg and Laurell $(1948,1951)$ considered that the $\mathcal{S}$ compound they isolated from human and pig $\omega$ blood and which they named caeruloplasmin was an $\alpha$ globulin. Thompson and Watson had 0 suggested from their experiments that copper $\Phi$ could be bound to each of the three main $\stackrel{\oplus}{+}$ globulins and we had supported this view by other $T$ earlier experiments. This opinion we find no $\stackrel{\vec{P}}{0}$ longer tenable in view of the results recorded here, $\stackrel{\curvearrowright}{\Omega}$ for it would appear to be established that $\stackrel{\otimes}{Q}$ caeruloplasmin is in the $F \alpha_{2}$ position and that the globulins as prepared by graded sodium sulphate 


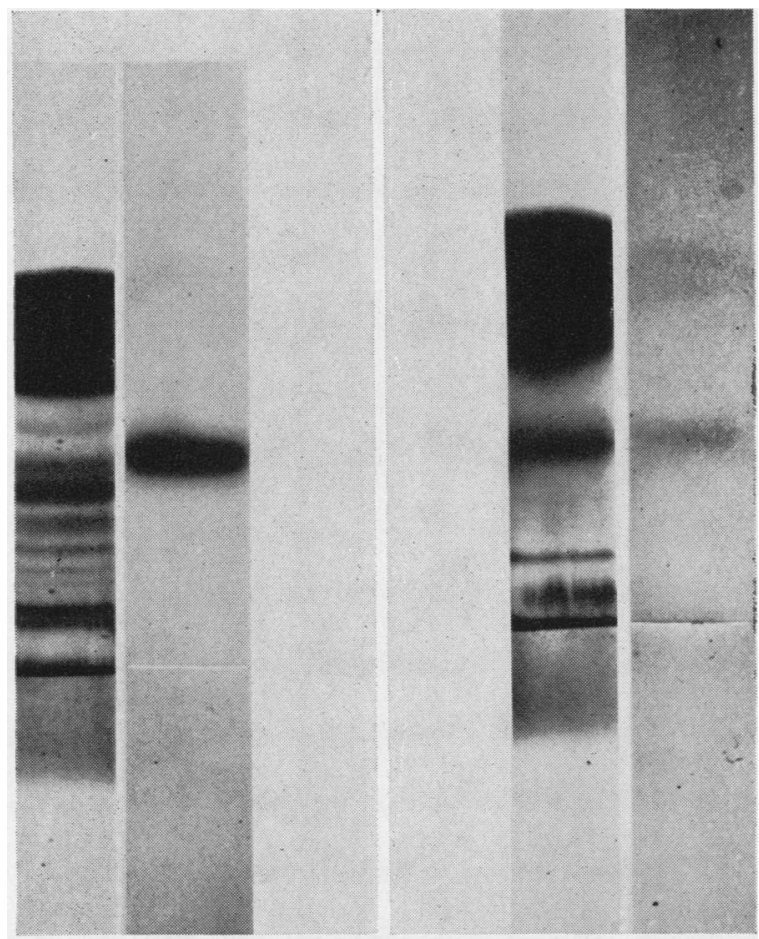

FIG. 3. - Starch gel electrophoresis of serum from a normal control (left) and from a patient with hepatolenticular degeneration (right) stained for protein and caeruloplasmin. precipitation are not as pure as had appeared on paper electrophoresis.

Uriel has described his findings relating to caeruloplasmin using a specific staining technique, but his preparations have been with agar and not starch.

The method employed by us might well be a useful screening technique in patients suspected of suffering from Wilson's disease. If serum is run in starch blocks and stained for both protein and caeruloplasmin, a comparison can be made between the sera of a normal control and of the patient. Fig. 3 demonstrates one of the cases which we have investigated together with a normal control and shows very clearly the difference between the two sera. It is also seen that both stained areas are in the $F \alpha_{2}$ position.

We wish to thank Messrs. R. Shortman and J. A. Mills for their excellent technical and photographic assistance respectively.

\section{REFERENCES}

Bearn, A. G., and Kunkel, H. G. (1954). Proc. Soc. exp. Biol. (N.Y.), $85,44$.

Cumings, J. N., Goodwin, H. J., and Earl, C. J. (1955). J. clin. Path., 8, 69.

Holmberg, C. H., and Laurell, C.-B. (1948). Acta chem. scand., 2, 550.

- (1951). Ibid., 5, 476.

Smithies, O. (1955). Biochem. J., 61, 629.

Thompson, R. H. S., and Watson, D. (1949). J. clin. Path., 2, 193. Uriel, J. (1958). Nature (Lond.), 181, 999. 